\title{
Inovação Cooperativa, Coworking e o Mercado de Cerveja Artesanal Fluminense
}

\author{
Cooperative Innovation, Coworking, and the Fluminense Craftbeer Market Beer
}

\author{
Elisa Priori de Deus ${ }^{1}$ \\ Orcid: https://orcid.org/0000-0002-1719-3959 \\ Carlyle Tadeu Falcão de Oliveira ${ }^{2}$ \\ Orcid: https://orcid.org/0000-0003-3603-1469
}

\begin{abstract}
Resumo
Os sistemas de coworking são espaços que oferecem flexibilidade para seus usuários com relação aos custos, e, por isso, seus principais atores são freelancers ou/e startups. As cervejarias ciganas, cervejarias sem fábricas que produzem no espaço da outra cervejaria, podem ser consideradas um modelo coworking. Os coworking cervejeiros fluminenses criam relações de parceria para produzir sua cerveja artesanal. Este trabalho procurou identificar a contribuição das cervejarias artesanais para a teoria da inovação cooperativa e do mercado cervejeiro. Para isso, utilizaram-se pesquisas bibliográfica, documental, entrevistas em profundidade e uma survey, cujos resultados foram analisados qualitativamente e por meio de estatística descritiva. Foram pesquisadas 154 microcervejarias fluminenses, sendo coletadas 15 entrevistas e 37 questionários. Observou-se que a inovação cooperativa nos coworking cervejeiros possibilita que pequenas empresas desenvolvam seu produto e ingressem no mercado, assim como a introdução de novas parcerias promove o fortalecimento da disseminação das cervejas artesanais entre os consumidores do estado do Rio de Janeiro, ao mesmo tempo que expande esse mercado para investidores, distribuidores, promotores comerciais e outros produtores de cerveja.
\end{abstract}

Palavras-chave: inovação cooperativa; coworking; cerveja artesanal cigana.

\begin{abstract}
Coworking systems are spaces that offer flexibility to their users concerning costs, and, therefore, their main actors are freelancers or/and startups. Gypsy breweries are breweries without factories that produce in the space of the other brewery, and it can be considered a coworking model. Coworking Fluminense brewers create partnership relationships to make their craft beer. This work sought to identify the contribution of craft breweries to the theory of collaborative innovation and the beer market, for this used bibliographic, documentary research and in-depth interviews, and a survey. We analyzed the results qualitatively and through descriptive statistics. 154 Fluminense microbreweries were researched, with 15 interviews and 37 questionnaires collected. It observed collaborative innovation in beer coworking allows small companies to develop their product and enter the market. As well as the introduction of new partnerships promotes the strengthening of the dissemination of craft beers among consumers in the state of Rio de Janeiro, at the same time, which expands this market to investors, distributors, commercial promoters, and other beer producers.
\end{abstract}

Keywords: cooperative innovation; coworking; gypsy craft beer.

\footnotetext{
${ }^{1}$ Universidade Federal Fluminense. E-mail: elisa.priori@coppead.ufrj.br

${ }^{2}$ UERJ / PPGAd - UFF. E-mail: carlyle.falcao@gmail.com
} 


\section{INTRODUÇÃO}

A história do capitalismo mostra que a evolução ocorre a partir da implantação de novos processos nos sistemas de produção, comercialização e financiamento. Há uma transformação contínua dos modelos antigos de produção para criação de novos fatores. Esse processo que Schumpeter chamou de destruição criadora é essencial e necessário para o desenvolvimento do capitalismo, pois é a partir dele que as organizações trabalham para se adaptar a novos fatores e garantir sua sobrevivência (SCHUMPETER, 1912:1997).

O Manual de Oslo (OECD,1997) afirma que inovar é muito mais que o desenvolvimento de produtos em um centro de pesquisa e desenvolvimento $(\mathrm{P} \& \mathrm{D}) \mathrm{da}$ organização. A inovação compreende diversas fases: científica, tecnológica, organizacional, financeira e comercial. Tais etapas envolvem atividades que englobam preparação para produzir, produção, preparação para o mercado, incluindo novas técnicas de marketing específicas para a implementação da inovação, ou novos métodos organizacionais que não necessariamente envolvam inovação de produto ou processo.

A inovação cooperativa demanda uma colaboração ativa das empresas envolvidas no processo de inovação. $\mathrm{O}$ conhecimento e a tecnologia precisam ser compartilhados pelas organizações parceiras a fim de que haja uma troca constante de informações que proporcione $o$ desenvolvimento de todas as empresas (OECD, 1997). As parcerias para cooperação permitem que empresas de diferentes portes participem da elaboração de novos projetos (TEECE, 1992).

O compartilhamento de bens/ serviços não foi criado no século XXI, ele está presente ao longo do seu desenvolvimento da sociedade. A troca de produtos ou serviços por outros é uma das formas de negociação mais antigas. A economia compartilhada é um fenômeno que facilita transações comerciais facilitando o acesso a um bem ou serviço, sem que haja compra/posse e, muitas vezes, até mesmo sem a troca monetária. Os sistemas de coworking são uma das formas da economia compartilhada ligada ao sistema de serviço e produto e ao estilo de vida colaborativo (BOTSMAN; ROGERS, 2011).

Coworking são locais desenvolvidos sob a base da sustentabilidade e da comunidade. Profissionais com flexibilidade de horário e espaço de trabalho se unem em um mesmo local para obterem melhores resultados - pessoal e profissional - do que trabalhando em seus próprios home offices. Esses espaços são procurados por pessoas que encontram a liberdade de trabalhar em qualquer ambiente, em diferentes horários, e estabelecem relações de confiança ao mesmo tempo em que ampliam suas redes de relacionamento (SPINUZZI, 2012).

Pesquisadores têm desenvolvido trabalhos relacionando inovação aberta com modelos de negócios ligados à economia compartilhada. Crowdfunding contribui para processos de inovação de produtos ao buscar avaliação externa dos patrocinadores do empreendimento - as pessoas que investem no negócio, pois elas são as primeiras a analisar o produto e apontar as necessidades de melhoria (STANKO; HENARD, 2017).

As organizações estão usando as plataformas de crowdsourcing e redes sociais colaborativas para encontrar novas soluções, desenvolver novos produtos e empreender colaborativamente em prol da inovação (PALACIOS; MARTINEZCORRAL; GRIJALVO, 2016; SERGIO; GONÇALVES, 2017).

No entanto, não encontramos estudos sobre o papel dos coworking (BOTSMAN; ROGERS, 2011; SPINUZZI, 2012) na construção de processos de inovação em empresas. Dessa forma, esta pesquisa visa contribuir com a literatura de 
inovação e coworking estudando esses dois conceitos integrados.

Este trabalho aborda o coworking pelo prisma da produção de cervejas artesanais, um mercado que está crescendo no Brasil. De acordo com a pesquisa realizada pelo Sindicato dos Fabricantes de Cerveja do Brasil (SINDICERV) no ano de 2014, o país tinha registrado em torno de 300 microcervejarias que movimentaram cerca de R $\$ 2$ bilhões naquele ano. No ano seguinte, houve um crescimento de $17 \%$ no número de microcervejarias, chegando ao número de 372 registradas no Ministério da Agricultura, Pecuária e Abastecimento (MAPA).

O MAPA divulgou uma pesquisa que o ano de 2017 terminou com o registro de 679 cervejarias que produziram 7,5 mil produtos diferentes. As cervejarias ciganas, uma modalidade de cervejaria, não possuem sua própria fábrica. Elas produzem alugando os equipamentos e serviços de cervejarias que têm espaço ocioso e estão dispostas a compartilhá-lo. (SEBRAE, 2015). Muitas microcervejarias são desse tipo. Trata-se de um mercado emergente em franca expansão e economicamente robusto.

Além disso, conforme o portal de Periódicos Capes, há em torno de 1100 artigos científicos que tratam sobre o sharing economy, sendo 96 que abordam o coworking pela perspectiva da sharing economy entre os anos de 2009 a janeiro/2019. No entanto, nenhum desses artigos trabalham o coworking sob o olhar do encontro das fábricas de cervejas artesanais com as cervejas artesanais ciganas.

Desse modo, surgiu a pergunta de pesquisa que orientou a presente investigação: qual é a contribuição das cervejarias artesanais para o mercado cervejeiro fluminense e para a teoria da inovação cooperativa?

Assim, o objetivo deste artigo foi identificar a contribuição das cervejarias artesanais para a teoria da inovação cooperativa e do mercado cervejeiro a partir dos coworking cervejeiros fluminenses. Para isso, foi necessário apresentar as teorias de inovação cooperativa e coworking, pesquisar e definir o mercado de cerveja artesanal, identificar e analisar os processos produtivos de cooperação inovativa desse setor. Em termos organizacionais, foram estudadas as cervejarias artesanais ciganas do estado do Rio de Janeiro, que são as cervejarias sem instalações próprias, e necessitam do espaço das cervejarias tradicionais com fábrica para a sua produção artesanal.

Este trabalho, além desta introdução, está dividido em uma revisão teórica, em que se trataram temas relacionados à pesquisa: inovação, economia compartilhada, coworking, cervejas artesanais e cervejarias ciganas. A metodologia utilizada é apresentada na terceira seção. $\mathrm{Na}$ quarta seção estão os resultados encontrados e a discussão à luz da teoria levantada. $\mathrm{O}$ artigo termina com as considerações finais na quinta seção seguido das referências bibliográficas.

\section{REFERENCIAL TEÓRICO}

\subsection{Inovação}

A inovação é constituída de múltiplos fatores, entre eles as mudanças das organizações, da economia e das pessoas na busca por aprimoramento contínuo. Além da exploração de novas formas de produção, novas matériasprimas, novas tecnologias e fornecedores, ampliação de mercados, parcerias e relações comerciais, novas estratégias de preço, de gerenciamento e de medição de desempenho (MAYO, 2003). Para Schumpeter (1997), as inovações iniciam no ambiente interno da organização através das transformações no ambiente que possibilitam a criação de novas ideias e o surgimento de novos conhecimentos.

O que impulsiona as transformações no sistema capitalista é a inovação através de novas combinações, ou seja, utilizar de maneira diferente os meios de produção que 
existem. Tais combinações advêm do desenvolvimento de um novo produto ou serviço, um novo método de produção, a criação de um novo mercado consumidor, uma nova fonte de matérias-primas ou simplesmente uma nova forma de organizar a produção (SCHUMPETER, 1912;1997).

O sistema capitalista é sustentado pelo desequilíbrio, não pelo equilíbrio como acreditavam os pensadores econômicos contemporâneos a Schumpeter. É a partir do desequilíbrio dinâmico que a transformação da atividade econômica é alcançada e o sistema capitalista se desenvolve. A inovação e o processo de destruição criadora são fundamentais para o progresso do capitalismo. É por meio da contínua instabilidade que os ciclos econômicos são transformados não ficando restritos à comercialização dos bens e/ou serviços, mas ao seu modo de produção e financiamento (SCHUMPETER, 1997).

Hoje, os limites das firmas estão cada vez mais difusos devido à capacidade de dividir as responsabilidades produtivas com empresas parceiras e há necessidade de acordos de cooperação entre as empresas a fim de que elas criem juntas novos produtos, processos e mercados. Essa cooperação possibilita que empreendimentos de tamanhos e recursos diversos possam trabalhar em novos projetos, possibilitando o processo inovativo ao utilizar uma rede de parcerias para o desenvolvimento de produtos e serviços (TEECE, 1992).

As inovações podem ser desenvolvidas por empresas com os seus próprios recursos ou em cooperação com outras empresas ou organizações públicas de pesquisa. Quando a inovação é realizada individualmente, demonstra que a empresa tem capacidade de se autossustentar por meio do seu capital financeiro, de pesquisa e desenvolvimento. Porém, quando a inovação é realizada por meio de um processo cooperativo, as atividades de inovação dependerão das relações estabelecidas para obtenção das fontes de informação, conhecimento, tecnologia, práticas, recursos humanos e financeiros (OECD, 1997).

Osterwalder e Pigneur (2010) no livro 'Business Model Generation' apresentam alguns modelos de negócios ligados à inovação e formas de buscá-la dentro das organizações. Entre esses modelos, destaca-se o que trata de negócio aberto e inovação aberta, de Chesbrough (2003). Para os autores, o negócio aberto produz inovação a partir do seu modelo de negócio que depende de organizações ou pessoas externas para se desenvolver, criar e capturar valor para o seu consumidor (OSTERWALDER; PIGNEUR, 2010).

Nos negócios abertos há a necessidade de cooperação entre organizações para o desenvolvimento delas, ou seja, se uma empresa tem produtos, serviços, tecnologia e/ou propriedade intelectual ociosa ela pode monetizá-lo construindo um novo projeto com outra organização. Essa inovação pode acontecer de dentro para fora ou de fora para dentro. Inovação de fora para dentro ocorre quando a organização traz ideias, projetos $\mathrm{e}$ recursos externos para desenvolver novos produtos, serviços ou processos. Inovação de dentro para fora é o contrário, a organização verifica recursos ociosos e dispõe para outras organizações e pessoas dando rentabilidade ao que está fora de uso (OSTERWALDER; PIGNEUR, 2010; VANHAVERBEKE; CHESBROUGH, 2014; $\quad$ BAGGIO; WEGNER; DALMARCO, 2018).

O modelo de negócio aberto (OSTERWALDER; PIGNEUR, 2010) potencializa a inovação a partir da capacidade de realizar parcerias, encontrar e desenvolver oportunidades não vista por outros, além de saber utilizar essas características de forma vantajosa para os negócios (VIEIRA; VALE; MAY, 2018). Não está vinculada à criação de novos mercados apenas, ela pode residir na transformação da forma de satisfazer mercados já existentes, ou seja, o empreendedor altera a sua percepção sobre a forma como a operação está ocorrendo e, 
com isso, modifica o processo de produção, comercialização ou logística de determinado bem ou serviço (TIDD; BESSANT; PAVIT, 2008).

A procura por aumentar seus recursos a fim de aprimorar os processos de inovação faz empresas de portes diferentes buscarem parceiros com perfis parecidos para as habilidades e capacidades que lhes faltam. Dessa forma, troca-se investimento por algo novo e pelo lucro, proporcionando acesso a novos recursos e o desenvolvimento de inovações. Desse modo, acelera-se também o acesso a um mercado diferenciado, o aumento de produção, e, ainda, há uma divisão dos riscos e custos que a inovação demanda (FARIA; LIMA; SANTOS, 2010).

Tidd, Bessant e Pavit (2008) afirmam que a inovação é sustentada pela capacidade de realizar parcerias, encontrar e desenvolver oportunidades não vistas por outros e saber utilizar essas duas características de forma vantajosa para os negócios. Com o surgimento da rede mundial de computadores, tornou-se possível explorar oportunidades como um leque de opções expandido, porque o uso dessa tecnologia atinge consumidores com diferentes perfis de consumo. A internet proporcionou uma cobertura do mercado consumidor maior, por meio de uma interação com o seu público de forma a contemplar uma experiência personalizada e especializada para cada segmento de público, alterando e ampliando as formas de inovar (TIDD, BESSANT E PAVIT, 2008).

\subsection{Economia Compartilhada-Coworking}

$\mathrm{O}$ termo sharing economy foi identificado em 2012, e a partir disso percebeu-se um aumento no número de publicações relativas ao assunto (SILVEIRA, PETRINI, SANTOS, 2016). Não há um conceito estabelecido sobre esse novo modelo econômico (BOTSMAN E ROGERS, 2011), mas um conjunto de estudos acerca do tema (HABIBI; DAVIDSON; LAROCHE, 2017;
WILHELMS; MERFELD; HENKEL, 2017; MILANOVA; MAAS, 2017) torna possível entender o seu funcionamento, suas premissas e alguns de seus formatos. Por isso, apresentam-se algumas definições de diferentes autores, alguns dos mais citados sobre o tema.

O compartilhamento acontece entre pessoas que têm a mesma maneira de pensar sobre o consumo promovendo $o$ desenvolvimento desse sistema de trocas, independente do bem ou serviço que será dividido. A troca pode fortalecer as relações humanas, uma vez que para compartilhar é necessário confiar. O consumidor deixa de pensar individualmente para preocupar-se com o coletivo (LAMBERTON, 2016).

Sharing economy é um fenômeno que facilita transações comerciais e possibilita o acesso a um bem e serviço, sem que haja compra/posse e, muitas vezes, até mesmo sem a troca monetária. É uma maneira de satisfazer as necessidades e desejos de forma mais sustentável e atraente, com baixo custo para o usuário. Tais atividades comerciais incluem transações de compartilhamento, empréstimo, aluguel, doação, trocas e escambo (BOTSMAN; ROGERS, 2011).

Há três formas de manifestação da economia compartilhada: i) mercados de redistribuição, quando ocorre uma transferência de propriedade, em que o bem não tem mais utilidade para o atual dono e este transfere sua posse para outra pessoa recebendo dinheiro ou outro produto na troca, evitando assim o descarte e incentivando sua reutilização; ii) os estilos de vida colaborativos, em que há a partilha de espaços e troca de ativos intangíveis, como tempo e habilidades; e o iii) sistemas de produtos e serviços, em que o usuário utiliza o bem sem necessidade de adquiri-lo, como compartilhamento de bicicletas, espaços de trabalho, carros - UBER, AIBNB e COWORKING integram as duas últimas formas (BOTSMAN E ROGERS, 2011).

Os sistemas de coworking são manifestações dos estilos de vida colaborativos, bem como, dos sistemas de 
produtos e serviços (BOTSMAN E ROGERS, 2011). Para este artigo elencaram-se algumas definições de coworking, principalmente de Spniuzzi (2012) para aplicá-los na análise do caso dos coworking cervejeiros fluminense.

Para Lumley (2014) os coworking são comunidades em que trabalhadores criativos e independentes são capazes de se unir para trabalhar lado a lado, sendo esse trabalho desenvolvido de maneira colaborativa ou independente, de acordo com sua necessidade.

Os espaços de coworking são locais que oferecem maior flexibilidade para seus usuários com relação aos custos de locação, por isso, seus principais trabalhadores são profissionais freelancers ou pequenas empresas e startups (RESE; KOPPLIN; NIELEBOCK, 2020). O coworking atrai pessoas que não dispõem de um capital de investimento elevado ou seu trabalho ainda está em fase inicial, o qual precisa ser testado no mercado. Os coworkers, ao ingressarem nesses sistemas, procuram contato e afinidade com os demais integrantes do grupo com intuito de criar parcerias e trocas profissionais e sociais. Eles buscam um estilo de organização horizontal, em que todos dividem as obrigações e benefícios, além de trocar experiências e criarem um networking que os possibilitem alcançar um desenvolvimento inovativo para seus negócios (SOARES E SALTORATO, 2015).

Devido à diversidade na construção dos espaços de coworking e do desenvolvimento poroso e instável das estruturas urbanas, tais locais podem consistir em espaços, que não necessariamente terão $\mathrm{o}$ aspecto de escritórios, mas ambientes em que bons parceiros se unam para realizar suas atividades. As definições aqui expostas deixam uma abertura conceitual sobre coworking, que pode abranger espaços físicos com projetos arquitetônicos diferentes, dependendo, somente, do desejo e dos objetivos dos seus usuários (SPINUZZI, 2012).

\subsection{Cerveja Artesanal}

A cerveja é uma das bebidas mais antigas que se tem registro. É a terceira bebida mais consumida no mundo, perdendo apenas para a água e o chá. No Brasil, o primeiro mestre cervejeiro chegou com a tripulação de Maurício de Nassau, em 1637, e três anos após a sua chegada foi inaugurada a primeira cervejaria das Américas em Recife, a La Fontaine (SILVA, 2017).

O Brasil é o terceiro maior produtor de cerveja do mundo, perdendo apenas para China e Estados Unidos. A cerveja é a bebida alcoólica mais consumida no país. Porém, para o SEBRAE (2015) há ainda mais espaços a serem explorados para ampliar e qualificar essa produção. O mercado cervejeiro denomina o tipo de cervejaria conforme a capacidade de produção e tradição de cada uma delas. A divisão comumente aceita é a descrita por Carvalho (2015):

a) Mega cervejarias Comerciais: produção de mais de 10 bilhões de litros de cerveja ao ano, concentrando a maior parte do mercado mundial. Exemplos dessa classificação: ABInbev e Heineken;

b) Cervejarias Grandes e Tradicionais: tem a produção acima de 1 bilhão de litros ao ano, e tem grande representatividade no mercado, como a Itaipava no Brasil;

c) Microcervejarias: produzem até 1,7 milhão de litros por ano, porém o seu produto apresenta características de produção diferenciada, agregada pela qualidade e tradição do local que será produzida, por exemplo, Noi de Niterói - RJ e Colorado de Ribeirão Preto - SP.

A cerveja artesanal caracteriza-se por sua produção ser em menor volume do que das indústrias tradicionais, mas, também, por privilegiar a fabricação através de processos manuais sem a utilização de conservantes. Seus ingredientes básicos são 
água, levedura, lúpulo e cevada maltada, porém, os mestres cervejeiros podem utilizar outros ingredientes para dar um sabor diferenciado à sua produção. A diversidade e o sabor original são os grandes atrativos da cerveja artesanal sendo o seu diferencial com relação às marcas vendidas em grande escala. Além disso, as cervejarias artesanais brasileiras são normalmente de origem familiar e há uma predominância da utilização do malte na sua produção. Por esse motivo, as cervejas dessa categoria costumam ser denominadas como cervejas premium ou especiais que atendem à demanda de um público que está disposto a gastar mais para beber um produto diferenciado (SEBRAE, 2016).

A produção de cerveja artesanal está presente em, praticamente, todo o território, com maior concentração de cervejarias nas regiões sul $(41 \%)$ e sudeste $(42 \%)$, com destaque para os estados do Rio Grande do Sul (142), São Paulo (124), Minas Gerais (87), Santa Catarina (78) e Rio de Janeiro (57) (MINISTÉRIO DA AGRICULTURA, PECUÁRIA E ABASTECIMENTO, 2018).

O mercado de cerveja artesanal estabeleceu um vínculo mais expressivo com as regiões Sul e Sudeste, as quais concentram $80 \%$ das cervejarias. $O$ estilo de produção das cervejas premium, também, está ligado à sua localização geográfica. Há uma preocupação para que cada região produza a cerveja artesanal com determinados atributos, com isso os cervejeiros buscam criar uma identidade na sua cerveja ligada às características de cada região (SEBRAE, 2016; ALVARENGA, 2018).

A Associação Brasileira de Cervejarias Artesanais (ABRACERVA) destaca que número de cervejarias no país (679 registradas) é diferente do número de rótulos existentes (8.903), ou seja, há um número maior de marcas do que de cervejarias (ALVARENGA, 2018). Tal fenômeno deve-se às cervejarias ciganas que produzem suas marcas nos espaços ociosos de outras cervejarias e apesar de estarem registradas no Ministério da Agricultura, Pecuária e Abastecimento (MAPA), não são contabilizadas por eles no levantamento sobre o mercado cervejeiro nacional (ABRACERVA, 2017).

$O$ modelo de produção cigano foi criado pelo dinamarquês Mikkel, sendo também denominado como cervejaria gypsy, colaborativa ou associada. Consiste no cervejeiro que não tem microcervejaria e aluga o espaço com os equipamentos de outra cervejaria (tradicionalmente uma microcervejaria) para produzir sua receita $\mathrm{e}$ comercializá-la. Ao longo desse processo, há uma troca de informações entre o mestre cervejeiro da casa com o contratante. Além disso, a microcervejaria que recebe a cervejaria cigana assume as responsabilidades legais junto a ANVISA e MAPA sobre cada receita produzida para o cervejeiro cigano. (GRANDO, 2014).

A vantagem ao tornar-se cigano é que o investimento inicial é em torno de 10 vezes inferior do que investir em uma fábrica própria. Dessa forma, os cervejeiros conseguem ampliar a produção, transformando a fabricação caseira em uma produção com escala para venda e de maneira profissionalizada (RONCOLATO, 2016).

O período em que o "cigano" fica na cervejaria contratada é como se fosse uma incubação para o desenvolvimento da marca e do canal de distribuição. Durante esse período, o cervejeiro cigano ainda não tem capital suficiente para cuidar desses dois itens que são importantes para 0 crescimento da sua cervejaria. $\mathrm{O}$ desenvolvimento da parceria entre $o$ cervejeiro cigano e a cervejaria com a fábrica é resultado do estabelecimento de relação de confiança e colaboração. Como efeito desse encontro está a busca por minimizar os seus custos, fomentar suas marcas e unir forças para que o mercado cervejeiro cresça no país. Dessa forma, entende-se que a relação estabelecida entre as duas marcas de cervejas propicie benefícios para ambos (RONCOLATO, 2016). Ou seja, consolida-se um coworking, 
pois uma fábrica com espaço e tempo ocioso disponibiliza essa ociosidade para outra empresa produzir.

\section{METODOLOGIA}

Para responder ao objetivo principal deste trabalho, que é verificar quais contribuições o mercado de cerveja artesanal traz de inovação para o processo produtivo dentro do seu próprio mercado sob a perspectiva dos coworking cervejeiros fluminenses, utilizou-se uma investigação exploratória acerca do mercado cervejeiro artesanal, principalmente sobre as cervejarias ciganas, e o seu modo de produzir.

Figura 1- Caminho Metodológico

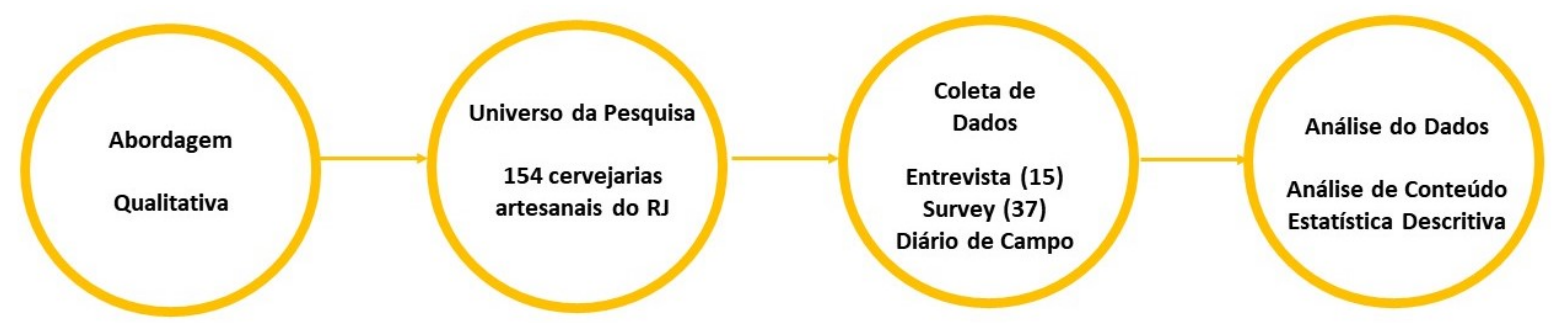

O estudo foi de caráter qualitativo com utilização de pesquisas bibliográfica, documental e de campo. A perspectiva qualitativa remete a uma ontologia e uma epistemologia subjetivista para analisar os dados empíricos. Os dados advindos da pesquisa empírica foram trabalhados sob a perspectiva interpretativista, na qual a realidade social é formulada sob a visão dos atores que estão engajados nela (BURREL \& MORGAN,1979).

As microcervejarias foram localizadas no estado do Rio de Janeiro pelas redes sociais por meio das páginas das cervejarias no Facebook e Instagram, normalmente, gerenciadas pelos próprios representantes. Foram encontradas 126 microcervejarias ciganas e 28 microcervejarias que têm suas fábricas $\mathrm{e}$ recebem os ciganos.

As entrevistas em profundidade foram realizadas com 15 microcervejarias, sendo 07 representantes das microcervejarias com fábricas que recebem ciganas, e 08 microcervejarias ciganas. Eles foram definidos utilizando os critérios estabelecidos por Vergara (1998, p. 49) acessibilidade e tipicidade, destaque no mercado e receptividade para a pesquisa.
A entrevista é utilizada em pesquisas exploratórias com objetivo de entender o problema de pesquisa, permitindo a criação de insights. Elas foram presenciais $\mathrm{e}$ semiestruturadas com algumas perguntas fechadas, para identificar o perfil do usuário dos coworking cervejeiros, e outras abertas a fim de que os entrevistados respondessem livremente sobre as questões levantadas, como as motivações e relevância da existência desses locais em que se compartilha os espaços de produção de cerveja. O roteiro das entrevistas foi baseado no referencial teórico estudado, assim como, as categorias de análise elaboradas. Elas aconteceram em duas fases: a primeira (piloto) foi realizada nos dias 24/09 e 04/10/2018 com dois sujeitos diferentes da pesquisa - dois sócios de uma cervejaria cigana e um dos sócios de uma fábrica que recebem as ciganas; a segunda fase, aconteceu nos dias 8/02 e 10/03/2019, quando foram entrevistados os demais responsáveis das ciganas e fábricas já com os ajustes no roteiro de entrevista por consequência das entrevistas piloto. $\mathrm{O}$ tempo médio das entrevistas foi de 50 minutos. 
Após as entrevistas, foi realizada uma survey com questionários on-line enviados a todas as outras microcervejarias com fábricas e ciganas que não participaram das entrevistas. Houve um retorno de 37 questionários respondidos, sendo 31 das microcervejarias ciganas e 04 das microcervejarias com fábrica.

$\mathrm{O}$ questionário on-line foi construído com base nos roteiros de entrevistas, mas com perguntas fechadas em que o respondente podia escolher apenas uma opção, em algumas perguntas, e assinalar mais de uma opção em outras. Nesse último caso, havia ainda a opção "outras" em que o respondente podia descrever a sua resposta.

Outras fontes contribuíram para a familiarização com o conceito de cervejarias ciganas. Buscou-se referências em documentos e reportagens que trouxeram mais esclarecimentos sobre $\mathrm{o}$ desenvolvimento desse mercado. Além disso, foram observadas algumas cervejarias ciganas em locais de vendas, como bares, feiras de gastronomia, eventos cervejeiros, e outros espaços em que foram encontrados cervejeiros ciganos oferecendo o seu produto ao consumidor.

A análise de conteúdo (BARDIN, 1977:2010) foi a balizadora das análises das entrevistas. Vergara (2005) destaca que a análise de conteúdo tem como pontos principais: unidades de análise, grade de análise, categorias, frequência dos elementos para pesquisas quantitativas, relevância dos elementos, presença ou ausência dos elementos. Assim como foi feito para o roteiro das entrevistas, o questionário também foi ajustado depois de testado com um responsável de uma cervejaria cigana e um responsável de uma fábrica que recebe as ciganas. $\mathrm{O}$ questionário foi disponibilizado para respostas do dia 11/03/2019 até o dia 01/04/2019.

Foi elaborada uma grade fechada para a análise dos dados com duas categorias definidas a priori: cerveja artesanal fluminense e inovação. O Quadro 01 retrata as categorias e subcategorias elaboradas, juntamente, com seus objetivos e referências.

Quadro 1- Categorias de Análise

\begin{tabular}{|c|c|c|c|}
\hline Categorias & Subcategorias & Objetivo & Referências \\
\hline Cerveja Artesanal & $\begin{array}{l}\text { - Relação Cigana e Fábrica } \\
\text { - Impactos para o mercado } \\
\text { de cerveja artesanal } \\
\text { fluminense. }\end{array}$ & $\begin{array}{l}\text { Entender como } \\
\text { funciona a relação } \\
\text { ciganas e fábricas, e os } \\
\text { resultados para o } \\
\text { mercado de cerveja } \\
\text { artesanal fluminense. }\end{array}$ & $\begin{array}{l}\text { Grando (2014); Sebrae } \\
\text { (2016); Roncolato } \\
\text { (2016); Martins (2016); }\end{array}$ \\
\hline Inovação & $\begin{array}{l}\text { · Novas Combinações: } \\
\text { produto, processo de } \\
\text { produção, mercado, e fonte } \\
\text { de matéria-prima } \\
\text { · Inovação por cooperação }\end{array}$ & $\begin{array}{l}\text { Inovar a partir da } \\
\text { cooperação trabalhando } \\
\text { em conjunto para o } \\
\text { desenvolvimento de um } \\
\text { novo mercado, produto, } \\
\text { processo ou fonte de } \\
\text { matéria-prima, } \\
\text { ampliando o mercado } \\
\text { de cerveja artesanal } \\
\text { fluminense. }\end{array}$ & $\begin{array}{l}\text { Schumpeter (1997), Tidd; } \\
\text { Bessant; Pavit (2008), } \\
\text { OECD (1997); Teece } \\
\text { (1992); Prahalad e } \\
\text { Krishiman (2008); } \\
\text { Osterwalder E Pigneur } \\
\text { (2010). }\end{array}$ \\
\hline
\end{tabular}

Fonte: Elaboração própria, 2018. 
O enfoque da análise dos dados foi na abordagem qualitativa em que $o$ pesquisador apresenta as relações existentes entre os elementos, dando destaque para os significados e o grau de importância que o conteúdo se manifesta nas falas e respostas de cada participante - entrevistado ou respondente. A interpretação dos dados se deu pela construção interativa de explicação, isto é, usamos as categorias estabelecidas para construir uma explicação apoiada nas relações entre elas. Tal método de interpretação é muito utilizado em pesquisas exploratórias (LAVILLE e DIONNE, 1999; VERGARA, 2005).

Os resultados da survey foram apresentados por meio da estatística descritiva. Com a utilização de um maior número de indivíduos, que atuam no mercado de cerveja artesanal fluminense, foi possível caracterizar melhor alguns aspectos das relações entre as cervejarias ciganas e os seus receptores, mas sem pretensão de se fazer inferências ou generalizações desse mercado, neste trabalho.

\section{RESULTADOS E DISCUSSÃO}

\subsection{Cerveja Artesanal}

Para se compreender qual é o resultado da interação das fábricas com as ciganas e vice-versa, buscou-se primeiro entender como os seus representantes conheceram o modelo de negócio de cervejaria cigana. As perguntas da pesquisa visaram compreender o impacto dessas relações no mercado de cerveja artesanal fluminense, por isso, investigou-se: quantas cervejarias ciganas a fábrica recebe de forma simultânea atualmente, bem como, quantas fábricas a cigana usa simultaneamente e qual o volume médio da produção das cervejarias ciganas. Investigou-se também quantos rótulos diferentes, ou seja, estilos de cervejas, os ciganos produzem atualmente. Para responder a essas questões, foram utilizadas transcrições de falas dos entrevistados como forma de exemplificar cada um dos resultados.

\subsubsection{Cervejarias Ciganas}

A relação entre ciganas e fábricas foi explorada a partir da pergunta como iniciou a produção e comercialização de cerveja artesanal. Nas entrevistas surgiram três maneiras que levaram os empreendedores cervejeiros a conhecerem o modelo cigano de produção.

1) Por contato direto com outros cervejeiros:

Eu comecei com meu primeiro cigano, com um cara que eu conheci em um curso lá em São Paulo, e conversando com ele, eu disse que estava montando uma fábrica, ele estava querendo montar uma marca também. Aí eu fiz duas levas minhas e uma (leva) dele e na verdade, ele está comigo até hoje. (Representante Fábrica 5).

2) Por meio de estudo de mercado para viabilizar uma oportunidade de negócio: "Quando eu voltei do curso que fiz eu comecei a correr atrás, pesquisar e fazer cursos de cervejarias. Desenvolvi cervejas com o Paulo..." (Representante Cigana 8).

3) Pelo conhecimento do mercado de cerveja artesanal e desejo em desenvolver o seu produto: "Quando você entra nesse mercado, você já entra conhecendo dois modelos de produção de cerveja. Ou você vai abrir a sua fábrica, ou você vai fazer uma terceirização da sua produção em uma outra fábrica" (Representante Fábrica 7).

As respostas sobre como os cervejeiros fluminenses conheceram $o$ modelo cigano vão ao encontro de como Grando (2014) descreveu o início da produção de cerveja de Mikkel. Os fluminenses procuraram uma alternativa para produzir a sua cerveja comercialmente sem ter o investimento inicial da construção de uma fábrica, além de contarem com todos os recursos e experiências dos cervejeiros que têm fábricas. Colocar uma evidência que comprove que há uma relação 
que constitui o coworking cervejeiro, e não demanda.

\subsubsection{Impactos para o mercado de cerveja artesanal fluminense}

Após estabelecer a maneira como eles produzem cerveja, buscou-se compreender como a união de ciganas e fábricas reflete no mercado de cerveja artesanal do estado do Rio de Janeiro. Por isso, questionou-se sobre volume e quantidade de estilos diferentes produzidos, bem como com quantas fábricas os ciganos trabalham e quantas ciganas as fábricas recebem.

Ao tratar do volume de produção e quantidade de rótulos produzidos, evidencia-se que a produção das fábricas e das ciganas são diferentes, uma vez que as fábricas têm capacidade de produção maior, podendo receber ciganos e produzir a sua cerveja ao mesmo tempo. O volume médio de produção mensal de uma cervejaria cigana ficou na faixa de 2 a 4 mil litros/mês, como informou o representante da Cigana 7, enquanto a produção das fábricas variou entre 9 a 12 mil litros, conforme representante da Fábrica 3.

Mesmo sendo uma fábrica, os volumes de produção mensal não a descaracterizam de ser uma produção artesanal, pois a produção de cerveja artesanal tem como natureza a produção em escalas menores e processos manuais (SEBRAE, 2016).

Nas entrevistas, na observação de feiras e eventos cervejeiros, notou-se que a produção de cerveja cigana não está restrita a apenas um estilo de cerveja, havendo uma diversificação de rótulos produzidos pelas ciganas dentro das fábricas. A média de produção relatada pelas ciganas entrevistadas foi de 7 rótulos diferentes ao longo de sua existência - "[...] linha fixa produzimos em 6." (Representante Cigana 3). Outra constatação é o fato que uma fábrica pode atender a mais de um cigano ao mesmo tempo. Ou seja, os estilos de cervejas apresentam números diversos para ciganas e para fábricas, pois apesar de trabalharem juntas as escalas são opostas, enquanto as ciganas produzem uma diversidade de rótulos em volumes menores, as fábricas permanecem com as suas próprias marcas buscando escalonar os seus produtos. Isso foi constatado durante as entrevistas.

A diversidade de estilos é uma característica das cervejas artesanais apresentadas pelo SEBRAE (2016). A cervejaria cigana fluminense, em especial, é exigida pelo mercado o lançamento de novos estilos sempre, como destacou o proprietário da fábrica 5 :

Cigano que já tem um ponto de venda, que já tem um bar, ele quer ter a cerveja dele. Por exemplo, os ciganos que eu tenho de São Paulo, normalmente, se eles têm três receitas, eles produzem as três receitas. Agora, cigano do RJ, toda hora está mudando. Daí eu já acho mais complicado. O mercado do RJ é diferente do de SP. No RJ, é um tentando fazer uma novidade mais impactante do que o outro. Para você ter uma ideia, eu tenho quarenta e dois produtos registrados na minha cervejaria. É muito para uma fábrica. Muitos desses ciganos são os que não repetem. (Representante Fábrica 5).

Torna-se perceptível, a partir da fala do representante da fábrica 5 , que o mercado fluminense de cerveja artesanal tem uma particularidade com relação aos demais: o de reivindicar das ciganas novos estilos de cerveja. É um mercado percebido de maneira diferenciada dos demais, pois para um novo cervejeiro entrar no mercado fluminense, ele necessita estar ciente dessa condição. Essa diferenciação por investir em novos produtos, com sabores e aromas diversificados é o que o SEBRAE (2016) retratou como a criação da identidade regional. Isso é, a identidade do mercado de cerveja fluminense está ligada às cervejarias ciganas inventarem novas receitas, explorando todo o potencial criativo do seu mestre cervejeiro. 
As fábricas, em sua maioria, conseguem atender mais de um cigano simultaneamente, mas isso não significa que todos os tanques dela serão utilizados por ciganos. A média de produção simultânea é de 3 ou 4 ciganas por fábrica que trabalha com suas marcas também: "[...] eu tenho sete tanques de fermentação. Normalmente desses sete, quatro estão com ciganos, e três, com cerveja minha" (Representante Fábrica 5).

Já nas fábricas que têm um foco no trabalho com os ciganos, como as fábricas 3 e 4, o espaço de produção simultânea é maior, como informou um dos respondentes: “[...] simultaneamente a gente atende até 9 , porque é o número de fermentadores que a gente tem. Na verdade, grande parte da nossa produção, mais ou menos $85 \%$ da nossa produção é cigana." (Representante Fábrica 3).

As ciganas, ao contrário do que se poderia crer por sua denominação estar relacionada a não ter um lugar fixo de residência, a metade das entrevistadas (4 ciganas) trabalham apenas com duas fábricas. $\mathrm{Na}$ outra metade, temos três ciganas que produzem com uma única cervejaria, e, somente uma cervejaria cigana afirmou que o seu conceito é de cigano nômade, ou seja, que produz sua cerveja com quantas fábricas for possível:

\section{[...] 4 atualmente 4, mas estamos indo para 5, 6 e 7 em breve. Conceito de cigano nômade, acho que uma coisa legal de falar que pode acrescentar a sua pesquisa existem duas coisas, é o cigano que é quem realmente quem roda, e quem faz indústria por terceirização - contract brewery. É uma coisa mais frequente $\operatorname{assim}[\ldots]$ a gente é cigano, cigano. A gente não para e se tiver oportunidade para algum lugar a gente vai. (Representante Cigana 1).}

O modelo cigano é um fenômeno com características heterogêneas. Os seus participantes buscam informações iniciais com os seus pares e outras fontes. Os volumes de produção e os estilos de cervejas variam de acordo com o tamanho de cada cervejaria e a relação cigana com as fábricas, que constituem os coworking cervejeiros. Parece ser essencial para o mercado de cerveja artesanal fluminense, haja vista o número de ciganas ser superior à quantidade de cervejarias com fábricas existentes no estado, conferindo a esse mercado uma característica ímpar em relação à diversificação de oferta de cervejas artesanais.

O processo de cerveja artesanal cigana no Rio de Janeiro não é um processo de arrendamento ou terceirização, pois os envolvidos relatam que há troca de informações e experiências durante a produção da cerveja. O coworking cervejeiro fluminense opera além do processo contratual. Os cervejeiros donos das fábricas ensinam os cervejeiros ciganos como é o funcionamento de uma produção em escala maior, sobre o processo de venda, e como o mercado funciona devido à sua experiência maior no mercado. Por outro lado, os cervejeiros ciganos empregam a novidade de produtos e serviços no mercado fluminense, e fazem os cervejeiros com fábricas quererem desenvolver novos produtos e processos de produção.

\subsection{Inovação}

$\mathrm{Na}$ categoria inovação, buscou-se aspectos ligados à inovação a partir da cooperação, onde a ideia de trabalhar em conjunto estimula o desenvolvimento de um novo mercado, produto, processo ou fonte de matéria-prima. Sendo assim, observando o referencial sobre o tema inovação encontramos duas subcategorias: as inovações que o modelo cigano propõe para o mercado de cerveja artesanal fluminense, ligadas aos preceitos schumpeterianos de inovação; e cooperação atrelada a novas formas de inovar com desenvolvimento em conjunto de ideias, produtos e tecnologias.

\subsubsection{As inovações que o modelo cigano propõe para o mercado de cerveja artesanal fluminense}


Segundo Schumpeter (1977), as inovações podem ser realizadas por meio de novas combinações que resultarão em novos produtos, processos, mercados ou fontes de matérias-primas. Essa subcategoria foi uma das mais encontradas na pesquisa, com 13 respostas que se relacionam com novas combinações. A resposta mais recorrente apresentou a afirmação de que as ciganas permitem que os consumidores tenham produtos diferentes, com uma variedade e qualidade de cervejas maior e melhor no mercado.

$\mathrm{O}$ representante da fábrica 2 destacou que:

\begin{abstract}
$\mathrm{Eu}$ acho que elas contribuem principalmente em uma coisa: criatividade. Quem tem fábrica, infelizmente, não pode viajar muito na criação de produto porque você tem muito medo de errar. O cigano é a ponte entre um consumidor que quer novidade e a novidade. Sempre é o cigano que aparece com alguma novidade e a fábrica executa. E essa novidade, na maioria das vezes, vira tendência. (Representante Fábrica 2).
\end{abstract}

Ao inserir um produto novo, o cigano oportuniza tendências no mercado de cerveja artesanal, dinamizando o setor e transformando os padrões de concorrência dentro da economia compartilhada. Desse modo, introduz-se uma inovação para o mercado de craftbeer que é o modelo dos coworking cervejeiros (BRASIL; NOGUEIRA; FORTE, 2011).

Quando a cigana cria uma variedade nova de cerveja pilsen ou stout com a inclusão de especiarias diversificadas para se diferenciar entre outras, ela está enriquecendo a experiência do consumidor ampliando suas possibilidades de degustação. Ao mesmo tempo, elas expandem o mercado de cervejas ao buscarem atender aos diversos paladares existentes. "Ah, é que com isso podem existir uma quantidade variada de cervejarias, apresentar mais cervejas para o público e aumentar o número de consumidores" (Representante Cigana 3); "variedade, novidade e hoje é um mercado amplo" (Representante Cigana 8).

A fala do representante da cigana 5 reforça o pensamento das ciganas 3 e 8 salientando que as ciganas lançam em um curto espaço de tempo uma cerveja nova. Assim, elas conseguem dar liberdade de escolha para os consumidores, enfrentando um mercado que há alguns anos era fechado e restrito às grandes indústrias.

Eu acho que elas trazem novas opções e possibilidades, principalmente aqui no Brasil, nós acabamos sendo dominados pelos grandes grupos cervejeiros, naquela velha política de serem exclusivos, querendo que no estabelecimento só tenha a cerveja deles, não tendo concorrência saudável, dificultando o trabalho local. Eu tinha um bar que a gente tinha contrato com uma empresa gigante que não nos deixava vender outra coisa, o cliente queria tomar algo diferente e não podia [...] São políticas que estão mudando. Então eu acho muito positivo. (Representante Cigana 5).

O representante da fábrica 6 atesta $o$ que disse o responsável da cigana 5, acrescentando a possibilidade de as cervejarias ciganas criarem tendências que poderão ser replicadas pelas fábricas e outras ciganas.

$\mathrm{Eu}$, como cliente cigano, eu, conhecendo três fábricas diferentes, eu vou conhecer pelo menos três formas diferentes de fazer a mesma coisa, podendo assim, escolher a mais eficiente, podendo passar isso para as outras. Boas ideias tendem a ser replicadas por vários produtores.... Como o cigano não tem muito compromisso em produzir volume ele não precisa ter tanto compromisso com repetitividade e pelo fato de que, geralmente, o custo fixo é menor do que uma cervejaria, ele consegue se aventurar mais. Ele pode se dar ao luxo de produzir novos produtos em um período menor de tempo. Isso com certeza traz o vigor em um mercado maior do que se fosse dominado por fábricas. (Representante Fábrica 6).

Para os representantes das fábricas o papel das ciganas é o de reinventar receitas, 
por isso o posicionamento das ciganas está ligado à qualidade do seu produto como diferencial referente à fábrica:

Porque permite a criação de novas marcas e permite a experimentação. $\mathrm{O}$ cigano tem essa coisa de arriscar mais. Para uma fábrica é muito arriscado experimentar coisas novas o tempo todo.... Eu acho que a qualidade. Como eles têm que concorrer com uma fábrica com um custo melhor, eles têm que investir em qualidade. Um cigano ruim, não sobrevive. Uma fábrica com uma cerveja ruim, consegue sobreviver. (Representante Fábrica 5).

A produção de cervejas singularizadas pelas ciganas só é possível pela união com as fábricas, caso contrário tais cervejas continuariam em produções caseiras sem venda ao público. É a expertise da fábrica que consegue ampliar o volume de produção das cervejarias ciganas. Os testes com novos ingredientes são produzidos em pouca quantidade e quando a cigana firma parceria de produção com a fábrica, cabe ao mestre cervejeiro responsável tornar a produção vendável sem perder a originalidade do sabor, do aroma e de outras características desenvolvidas pela cigana.

Novas combinações operacionais no mercado cervejeiro fluminense também encontram-se nos arranjos para melhorar as condições de distribuição dos produtos, na contratação de um comercial em conjunto, ou seja, na produção coletiva de marketing:

Existem grupos de venda, então assim se juntam 4 cervejarias ou 6 ou mais... e pegam o vendedor, e fazem uma tabelinha, instruem ele, dão uma guiada.... Outra coisa que acontece, a distribuição terceirizada é muito difícil para uma cervejaria fazer, existe um player no mercado que é distribuidora. Existem algumas você manda, elas acumulam de algumas cervejarias, e para você vai no ponto de venda, não tem o porquê eu ir, Davi ir, ou coisa assim.... Centraliza com eles lá, e eles fazem a entrega e a gente paga para eles [...] (Representante Cigana 1).
O modelo cigano impulsiona alterações no mercado de cerveja artesanal ao usar meios de produção existentes de maneira diferente. Essas combinações envolvem um vendedor que trabalha para um grupo de cervejarias ciganas. Os proprietários trabalham juntos na potencialização desse player, e ele atua na venda para todos minimizando os custos e ampliando as potencialidades de negócios.

Nesse sentido, o modelo cigano também aprimora a distribuição no mercado de cerveja artesanal com a criação de distribuidores profissionais que atendam às demandas ciganas e a de cervejas de fábrica. Assim, devido às necessidades dos cervejeiros ciganos, novos atores surgem ou se aprimoram no mercado de cerveja artesanal. $\mathrm{O}$ arranjo dessas novas dinâmicas são inovações específicas para o mercado de craftbeer, segundo os preceitos de Schumpeter (1977).

Além de aprimorar os atores do mercado de cerveja artesanal, para quase a totalidade dos respondentes (12), as cervejarias ciganas promovem e desenvolvem o mercado de cerveja artesanal fluminense junto aos consumidores. Elas fomentam a cultura cervejeira ao se permitirem arriscar nas suas receitas, ao elaborar sabores e aromas diferenciados tendo um custo e volume menor de produção, utilizando as instalações e a competência das pessoas que já saíram do momento cigano, e agora produzem em fábricas próprias.

Explorar novas formas de produzir, novas matérias-primas, novas receitas faz os ciganos ampliarem o mercado, as parcerias e as relações comerciais, além de trazer para o mercado novas estratégias de preço, gerenciamento, medidas de desempenho e ferramentas de marketing (MAYO, 2003).

A resposta do representante da cervejaria cigana 3 reforça essa ideia:

É que com isso pode existir uma quantidade variada de cervejarias, apresentar mais 
cervejas para o público e aumentar o número de consumidores, poder mostrar a cerveja para o público e crescer o mercado. Se não fosse por isso, vários de nós não poderiam existir. (Representante Cigana 3).

O modelo cigano de produção amplia, também, o número de cervejeiros no mercado, permitindo que novos produtores lancem e vendam seus produtos para depois deixarem a produção caseira. Dessa maneira, o mercado disponibiliza mais possibilidades para o consumidor. Os representantes das fábricas reforçam a ideia do acesso aos mercados de cerveja artesanal no estado: "É a popularidade; permite que qualquer pessoa consiga entrar no mercado" (Representante Fábrica 5).

A contribuição principal das cervejarias ciganas para o mercado de cerveja artesanal percebida pelos dois participantes dessa relação é desenvolver a cultura da cerveja artesanal. Isso ocorre por dois motivos: o baixo custo de se entrar em um mercado sem necessitar financiar suas próprias instalações e a exigência do mercado fluminense sempre ávido por rótulos novos.

$\mathrm{Na}$ verdade, o período de coworking dos cervejeiros fluminenses é uma transição para que as cervejarias ciganas construam a sua marca e desenvolvam o seu produto para abrirem suas próprias fábricas em breve.

\subsubsection{Colaborar para Inovar}

A colaboração promove inovação no mercado de cerveja artesanal cigana de diversos modos segundo os entrevistados: as fábricas estão em busca de adquirirem conhecimento, quando abrem suas portas aos ciganos, por meio de uma relação transparente e confiável; os ciganos, por sua vez, unem-se a fábricas para conseguir redução de custos nas matérias-primas e produção ou ainda obter outras vantagens como o marketing e a logística para seus produtos.

O proprietário da fábrica 1 compartilha com os ciganos ideias, experiências e o seu espaço, não só para produzir, mas para ser mais um ponto de venda para os dois. Inovar sob entendimento da cooperação é um processo dinâmico em que o conhecimento é adquirido por meio da interação (OECD, 1997).

As cervejarias com fábrica e as cervejarias ciganas são pequenas ou microempresas, dessa maneira inovar sozinho torna-se inviável. Quando existe a cooperação entre as partes, eles conseguem desenvolver novos produtos ou serviços de maneira mais sustentável para os seus negócios (BAGGIO; WEGNER; DALMARCO, 2018).

A cooperação de duas ou mais cervejarias na produção de uma cerveja colaborativa pode ser considerada uma nova combinação (SCHUMPETER, 1977), pois da união de duas organizações elaborase um produto novo por meio da criação de um novo processo de produção. Há cooperação entre concorrentes para o desenvolvimento de algo novo para o mercado, seja processo ou produto, conforme Begston e Kock (1999), ou o desenvolvimento de uma nova estratégia de marketing (OECD, 1997), como o uso das redes de relacionamento das organizações participantes do coworking para $\mathrm{o}$ lançamento de produtos.

A proprietária da fábrica 7 reforça o sentido da colaboração ao dizer que desenvolve uma relação salutar com os seus clientes ciganos, explicando como é o mercado e se ele realmente está preparado para vender a produção que está solicitando produzir na fábrica dela. "[...] isso porque eu não tenho a intenção de produzir a qualquer custo. Eu quero que uma produção seja saudável para os dois lados. A maioria das fábricas não pensa assim. Eu não acho que uma relação diferente ajuda no mercado." (Representante Fábrica 7). 
A relação estabelecida pela proprietária da fábrica 7 , com os ciganos que recebe, é de compartilhamento de informações que possibilita o crescimento dos dois lados. Dessa maneira, a cooperação trabalha em prol da inovação, pois não há competição, mas compartilhamento que permite o aperfeiçoamento do produto, do processo de produção, do canal de distribuição, da estratégia de marketing, ou da criação de uma nova cervejaria (OECD, 1997).

O processo de inovação estabelecido entre as cervejarias ciganas e fábricas pode ser classificado como colaboradores integrados (LAZZAROTTI et al., 2011). As duas partes comungam todos os passos do processo de inovação com parceiros específicos que produziram a cerveja. Há uma troca de conhecimento que beneficia as duas partes envolvidas na inovação (CARVALHO; SUGANO, 2016).

As respostas advindas dos ciganos estão voltadas para a redução de custos que eles obtêm ao se unirem. Um dos exemplos é a compra de insumos e a participação em eventos. "Várias parcerias surgem e às vezes existem fábricas que juntam vários ciganos, o que diminui o custo [...] muito essa questão de parceria também" (Representante Cigana 2); "viabiliza nosso desejo de ter uma cerveja de qualidade. A nossa, por exemplo, possui quatro prêmios nacionais, então você consegue ter um produto de excelência, um produto que você pode distribuir para o Brasil" (Representante Cigana 6). Desse modo, o modelo cigano inova através da cooperação quando suas relações não são verticais, mas horizontais (JORDE; TEECE, 1990; BEGSTON; KOCK, 1999).

As relações são a base para inovação no setor de cerveja artesanal fluminense. As relações horizontais transformam amizades em parcerias de negócios, e proporcionam que eles encontrem oportunidades de inovar, melhorar suas capacidades e competências, aprimorar seus modelos de negócio. Por meio da colaboração entre as relações, os produtores de cerveja artesanal fluminense trocam conhecimento e produzem inovação (VIEIRA; VALE; MAY, 2018).

As cervejarias ciganas, por serem um modelo de negócio aberto, segundo Osterwalder e Pigneur (2010), dependem das fábricas para se desenvolverem e criarem valor às suas marcas. Nos negócios abertos, a cooperação entre as organizações é necessária e pode ocorrer de diversas maneiras, como: trocas de tecnologias, serviços ou a elaboração de uma nova cerveja.

Inovar em negócios abertos pode ser de dentro para fora, quando a fábrica verifica que tem recursos ociosos e disponibiliza para a cigana, dando rentabilidade para o que estava sem uso. $\mathrm{Ou}$ de fora para dentro, quando a cigana divide sua criatividade e juntos desenvolvem uma cerveja diferenciada que pode vir a ser tendência no mercado de cerveja artesanal (OSTERWALDER; PIGNEUR, 2010).

\section{CONSIDERAÇÕES FINAIS}

A fim de responder à pergunta: quais contribuições o mercado de cerveja artesanal apresenta de inovação para o seu processo de produção? este trabalho elencou algumas definições sobre cerveja artesanal cigana, coworking e inovação cooperativa. $\mathrm{O}$ processo de produção das cervejarias ciganas dentro do mercado de cerveja artesanal, por meio dos coworking cervejeiros, permite responder quais são as contribuições que a inovação cooperativa pode suscitar.

A inovação cooperativa é apresentada pela pesquisa da produção de cerveja artesanal. As cervejarias ciganas na sua concepção dependem da consolidação desse modo de se relacionar para que existam e, consequentemente, desenvolvam-se.

As cervejarias ciganas promovem a inovação cooperada dentro do mercado de cerveja artesanal por intermédio dos coworking cervejeiros, em que os ciganos e as fábricas compartilham espaços, 
equipamentos e insumos de produção. Para além, da divisão dos itens físicos, há troca de conhecimento, de informações, de experiências, de estilos de vida e valores. Há colaboração para atingir os objetivos de todos os parceiros envolvidos.

Os cervejeiros ciganos estabelecem iniciativas que fomentam o mercado em que eles estão inseridos de maneira benéfica para produtores (ciganos e fábricas) $\mathrm{e}$ consumidores. Ao relatarem o desejo de construir um senso de comunidade ou uma parceria, ampliam a visão do mercado de cerveja artesanal fortalecendo seus negócios.

Os coworking cervejeiros assemelham-se a uma incubadora para as cervejarias. Durante o período cigano, os cervejeiros por não terem a obrigação de manter uma fábrica e suas despesas, bem como se responsabilizar legalmente pelas receitas, desenvolvem melhor o seu mix de marketing - produto, marca, promoção e distribuição aos mercados.

Para os dois participantes desse ciclo da economia compartilhada, fábricas e ciganas, a maior contribuição das ciganas para o mercado de cerveja artesanal fluminense é fomentar o mercado. Isso é, as cervejarias ciganas criam cervejas novas, buscam novos mercados e parceiras para ampliar o seu leque de vendas, além de mostrarem para outros cervejeiros caseiros que é possível tornar-se uma cervejaria profissional e colocar no mercado a cerveja que é produzida na sua casa.

As cervejarias ciganas atuam como atores que mostram que é possível ter um negócio, mas que para isso é preciso, inicialmente, obter redes de colaboração e cooperação para o seu desenvolvimento. Durante as entrevistas, o que foi percebido é a transitoriedade do modelo cigano, pois a maioria das cervejarias trabalham para conseguir ter sua fábrica própria. Dessa forma, nota-se que o ciclo das cervejarias ciganas fluminenses é muito dinâmico, pois há sempre novos entrantes. $\mathrm{O}$ modelo de cervejarias ciganas está espalhado por todo o estado e as motivações podem ser diferentes com a abertura de uma fábrica, mudança do cigano para outro estado, fechamento da cigana, mas sempre há novas cervejarias ciganas surgindo e fábricas recebendo ciganas. $\mathrm{O}$ ciclo da economia compartilhada se mantém em alta atividade, pois há sempre dois participantes nesse mercado buscando o mesmo objetivo, o de produzir cervejas diferenciadas.

Dessa forma, esta pesquisa vem acrescentar mais conhecimento às áreas temáticas de coworking e inovação compartilhada em um setor pouco estudado que é o mercado de cervejas artesanais. Do ponto de vista gerencial, apresentou-se diversas perspectivas do negócio do modelo cigano de cerveja para degustadores, investidores, distribuidores, promotores comerciais e produtores de cerveja.

Reconhece-se que o estudo foi realizado em uma perspectiva qualitativa e que o aumento de respondentes em uma amostra maior de cervejeiros por técnicas quantitativas poderia aumentar a robustez dos resultados com possibilidade de expandi-lo para todo o mercado de cervejas artesanais fluminenses. Essa pesquisa quantitativa seria um interessante estudo a ser realizado, bem como entender melhor o processo produtivo artesanal da cerveja, já que não foi possível realizá-lo neste estudo. Pela diversidade dos atores e suas relações em torno desse negócio, pesquisas na área de marketing seriam bem-vindas para poder se compreender melhor esse promissor e inovativo mercado de cervejas.

\section{REFERÊNCIAS}

\section{ABRACERVA. Com 91 novos registros no $1^{\circ}$ semestre, o mercado das artesanais avança no Brasil e já tem 610 cervejarias. 2017. Disponível em: http://abracerva.com.br/com-91-novos- registros-no-10-semestre-mercado-das- artesanais- avanca-no-brasil-e-ja-tem-610- cervejarias . Acesso em: 12 jan. 2018.}

\section{ALVARENGA, Darlan. Número de Cervejas no Brasil quase dobra em 3}


anos e o setor volta a criar empregos. 2018. Publicada Por Portal G1. Disponível em:

https://g1.globo.com/economia/pme/notici a/numero-de-cervejarias-no-brasil-quasedobra-em-3-anos-e-setor-volta-criarempregos.ghtml. Acesso em: 30 mar. 2018.

BAGGIO, Daniela; WEGNER, Douglas; DALMARCO, Gustavo. Coordination mechanisms of collaborative $R \& D$ projects in small and medium enterprises. RAM. Revista de Administração Mackenzie, v. 19, n. 2, 2018.

BARDIN, Laurence. Análise de conteúdo. (1977). Lisboa (Portugal): Edições, v. 70, p. 225,2010 .

BENGTSSON, Maria; KOCK, Sören. Cooperation and competition in relationships between competitors in business networks. Journal of business \& industrial marketing, 1999.

BOTSMAN, R. ROGERS, R. O que é meu é seu: como o consumo colaborativo vai mudar o nosso mundo. Porto Alegre: Bookman, 2011.

BRASIL, Marcus Vinicius de Oliveira; NOGUEIRA, Cláudio André Gondim; FORTE, Sérgio Henrique Arruda Cavalcante. Schumpeter e o desenvolvimento tecnológico: uma visão aplicada às pequenas e médias empresas. Revista de Ciências da Administração. v. 13, n. 29, p.38-62, 20 abr. 2011. DOI http://dx.doi.org/10.5007/21758077.2011v13n29p38.

BURREL, Gibson \& MORGAN, Gareth. Sociological paradigms and organizational analysis. Heinemann: London, 1982.

CARVALHO, Naiara Barbosa. Cerveja Artesanal: pesquisa mercadológica e aceitabilidade sensorial. 136 f. 2015. Tese
(Doutorado). Universidade Federal de Viçosa, Viçosa, MG, 2015.

CARVALHO, Eduardo; SUGANO, Joel. Tipologias de inovação aberta em novas empresas de base tecnológica brasileiras. Revista Portuguesa e Brasileira de Gestão, v. 15, n. 2, p. 65-83, 2016.

CHESBROUGH, Henry William. Open innovation: The new imperative for creating and profiting from technology. Harvard Business Press, 2003.

CHESBROUGH, Henry; VANHAVERBEKE, Wim; WEST, Joel (Ed.). New frontiers in open innovation. Oup Oxford, 2014.

FARIA, Pedro de; LIMA, Francisco; SANTOS, Rui. Cooperation in innovation activities: The importance of partners.

Research Policy, [s.1.], v. 39, n. 8, p.10821092, out. 2010. Elsevier BV.

http://dx.doi.org/10.1016/j.respol.2010.05. 003. Disponível em:

https://www.sciencedirect.com/science/arti cle/pii/S0048733310001277. Acesso em: 03 ago. 2018.

FREITAS, Henrique et al. O método de pesquisa survey. Revista de

Administração da Universidade de São Paulo, v. 35, n. 3, 2000.

GIL, Antônio Carlos. Métodos e Técnicas de Pesquisa Social. 6. ed. São Paulo: Atlas, 2008.

GRANDO, João Weber. Dinamarquês cria cervejas de forma 'cigana' e com fábricas emprestadas. 2014. Disponível em:

http://www1.folha.uol.com.br/comida/201 4/06/1468189-dinamarques-cria-cervejasde-forma-cigana-e-com-fabricasemprestadas.shtml. Acesso em: 12 jan. 2018. 
HABIBI, Mohammad Reza; DAVIDSON, Alexander; LAROCHE, Michel. What managers should know about the sharing economy. Business Horizons, v. 60, n. 1, p. 113-121, 2017.

JORDE, Thomas M.; TEECE, David J.. Innovation and Cooperation: Implications for Competition and Antitrust. The Journal of Economic Perspectives, Berkeley, v. 4, n. 3, p.75-96, jun. 1990. Disponível em: https://www.jstor.org/stable/1942930. Acesso em: 03 ago. 2018.

LAMBERTON, Cait. Collaborative consumption: a goal-based framework.

Current Opinion In Psychology, [s.1.], v. 10, p.55-59, ago. 2016. Elsevier BV. http://dx.doi.org/10.1016/j.copsyc.2015.12. 004. Disponível em:

https://www.sciencedirect.com/science/arti cle/pii/S2352250X15003115?via=ihub.

Acesso em: 11 set. 2017.

LAVILLE, C.; DIONNE, J. A construção do saber: manual de metodologia da pesquisa em ciências humanas. Belo Horizonte: UFMG, 1999.

LAZZAROTTI, Valentina; MANZINI, Raffaella; PELLEGRINI, Luisa. Firmspecific factors and the openness degree: a survey of Italian firms. European Journal of Innovation Management, v. 14, n. 4, p. 412-434, 2011.

LUMLEY, Risa M.. A Coworking Project in the Campus Library: Supporting and Modeling Entrepreneurial Activity in the Academic Library. New Review Of Academic Librarianship, [s.1.], v. 20, n. 1, p.49-65, jan. 2014. Informa UK Limited. http://dx.doi.org/10.1080/13614533.2013.8 50101. Acesso em: 10 nov. 2017.

MARTINS, Eduardo da Silva. Panorama Da Produção De Cerveja Em Porto Alegre E Sua Terceirização: As Relações Entre Microcervejarias E Cervejarias
Contratantes. 2016. 66 f. TCC (Graduação)

- Curso de Administração de Empresa, Departamento de Ciências

Administrativas, UFRGS, Porto Alegre,

2016. Disponível em:

http://www.lume.ufrgs.br/handle/10183/15

8582. Acesso em: 12 jan. 2018.

MATTAR, F.N Pesquisa De Marketing.

São Paulo: Atlas, 1994

MAYO, A. Inovação e aprendizagem. In: MAYO, Andrew. O valor humano da empresa. São Paulo: Prentice Hall, 2003. p. $150-171$.

MILANOVA, Veselina; MAAS, Peter. Sharing intangibles: Uncovering individual motives for engagement in a sharing service setting. Journal of Business Research, v. 75, p. 159-171, 2017.

MINISTÉRIO DA AGRICULTURA, PECUÁRIA E ABASTECIMENTO (MAPA). Anuário da cerveja. Disponível em: https:/www.gov.br/agricultura/ptbr/assuntos/noticias/a-cada-dois-dias-umanova-cervejaria-abre-as-portas-no-brasil. Acesso em: 12 jan. 2018.

OECD. Manual de Oslo: diretrizes para coleta e interpretação de dados sobre inovação. 3. ed. Oslo: Finep, 1997. 184 p. Traduzido sob a responsabilidade da FINEP.

OSTERWALDER, A.; PIGNEUR, Y. Business Model Generation. Hoboken: John Wiley \&

Sons, 2010.

PALACIOS, Miguel et al. Crowdsourcing and organizational forms: Emerging trends and research implications. Journal of Business Research, v. 69, n. 5, p. 18341839, 2016.

PRAHALAD, C.k.; KRISHMAN, M.s. A nova era da Inovação: Impulsionando a co-criação de valor ao longo das redes 
sociais. Tradução Afonso Celso da Cunha Serra. Rio de Janeiro: Elsevier, 2008. 242 p.

RESE, Alexandra; KOPPLIN, Cristopher Siegfried; NIELEBOCK, Caren. Factors influencing members' knowledge sharing and creative performance in coworking spaces. Journal of Knowledge Management, 2020.

\section{RISEN, C. The Innovative 'Gypsy} Brewers' Shaking Up the Beer World. The Atlantic, 20 Oct 2010. Disponível em: http://www.theatlantic.com/health/archive/ 2010/10/theinnovative-gypsy-brewersshaking-up-the-beer-world/64828/. Acesso em: 07 Jan 2019.

RONCOLATO, Murilo. Cerveja artesanal avança no Brasil com pequenos e 'ciganos'. 2016. Jornal digital Nexo. Disponível em: https://www.nexojornal.com.br/reportagem /2016/12/16/Cerveja-artesanal-avança-noBrasil- com-pequenos-e- 'ciganos'. Acesso em: 15 jan. 2018.

\section{SEBRAE. Boletim- Potencial de} consumo de cervejas no Brasil. 2015. Disponível em: http://www.sebraemercados.com.br/boleti m-potencial-de-consumo-de-cervejas-nobrasil/. Acesso em: 12 jan. 2018.

SEBRAE. Microcervejarias. 2016.

Disponível em:

http://www.bibliotecas.sebrae.com.br/chro nus/ARQUIVOS_CHRONUS/bds/bds.nsf/ 8818d2954be64fcda8628defef1f70f8/\$File 17503.pdf. Acesso em: 12 jan. 2018

SCHUMPETER, Joseph. A teoria do desenvolvimento econômico (1912). São Paulo: Ed, 1997.

SERGIO, Marina Carradore; GONÇALVES, Alexandre Leopoldo. Inovação aberta: o potencial das redes sociais colaborativas na gestão de ideias.
Informação \& Sociedade, v. 27, n. 3, 2017.

SILVA, Eduardo. Mercado de Cerveja Artesanal acompanha a evolução do shopper para inovar e crescer. 2017. Clube do Trade. Disponível em: https://clubedotrade.com.br/blog/mercadode-cerveja-artesanal/. Acesso em: 12 jan. 2017.

SILVEIRA, Lisilene Mello da; PETRINI, Maira; SANTOS, Ana Clarissa Matte Zanardo dos. Economia compartilhada e consumo colaborativo: o que estamos pesquisando? Rege - Revista de Gestão, [s.1.], v. 23, n. 4, p.298-305, out. 2016. Emerald. http://dx.doi.org/10.1016/j.rege.2016.09.00 5. Disponível em: https://linkinghub.elsevier.com/retrieve/pii/ S1809227616306063. Acesso em: 21 nov. 2017.

SOARES, Juliana Maria Moreira; SALTORATO, Patrícia. Coworking, uma forma de organização de trabalho: conceitos e práticas na cidade de São Paulo. Atoz: novas práticas em informação e conhecimento, v. 4, n. 2, p.61-73, 2015. http://dx.doi.org/10.5380/atoz.v4i2.42337. Acesso em: 10 nov 2017.

SPINUZZI, C. (2012). Working alone together: coworking as emergent collaborative activity. Journal of Business and Technical Communication, 26(4), 399-441. Doi: 10.1177/1050651912444070

STANKO, Michael A.; HENARD, David $\mathrm{H}$. Toward a better understanding of crowdfunding, openness and the consequences for innovation. Research Policy, v. 46, n. 4, p. 784-798, 2017.

TEECE, David J. Competition, cooperation, and innovation. Journal Of Economic Behavior \& Organization, [s.1.], v. 18, n. 1, p.1-25, jun. 1992. 
Elsevier BV. DOI

http://dx.doi.org/10.1016/0167-

2681(92)90050-1. Disponível em:

https://www.sciencedirect.com/science/arti

cle/pii/016726819290050L. Acesso em: 03

ago. 2018.

TIDD, Joe; BESSANT, John; PAVIT,

Keith. GESTÃO DA INOVAÇÃO. 3. ed.

Tradução: Elizamari Rodrigues Becker,

Gabriela Perizzolo, Patricia Lessa Flores

Da Cunha, Sara Viola Rodrigues,

Semframis Teixeira Bastos. Porto Alegre:

Bookman, 2008. 600 p.

VERGARA, Sylvia Constant. Projetos e

Relatórios de Pesquisa em

Administração. 2. ed. São Paulo: Editora

Atlas S.A, 1998. 87 p.
VERGARA, Sylvia Constant. Métodos de

Pesquisa em Administração. São Paulo:

Editora Atlas S.A., 2005. 269p.

VIEIRA, Filipe C.; VALE, HAMILCAR V.; MAY, Marcia R. Open Innovation And Business Model: Embrapa Forestry Case Study. RAM. Revista de Administração Mackenzie, v. 19, n. 4, 2018.

WILHELMS, Mark-Philipp; MERFELD, Katrin; HENKEL, Sven. Yours, mine, and ours: A user-centric analysis of opportunities and challenges in peer-topeer asset sharing. Business Horizons, v. 60, n. 6, p. 771-781, 2017.

\footnotetext{
${ }^{i}$ Elisa Priori de Deus

Doutoranda em Administração na Universidade Federal do Rio de Janeiro (UFRJ).

Mestre em Administração na Universidade Federal Fluminense (UFF), com financiamento da CAPES - Bolsista. Especialista em Negócios Digitais pela UNIRITTER. Graduada em Comunicação Social Relações Públicas pela Universidade Federal do Rio Grande do Sul (UFRGS). Tem como interesse de pesquisa os temas: economia compartilhada, sistemas de coworking, cerveja artesanal, cerveja artesanal cigana, inovação, redes de inovação, comportamento do consumidor, cultura e consumo, mídias e consumo, marketing de experiência.

\section{ii Carlyle Tadeu Falcão de Oliveira}

Doutor em Administração pela Escola de Administração Pública e de Empresas da Fundação Getúlio Vargas - EBAPE/FGV. Professor adjunto da Faculdade de Administração e Finanças da Universidade do Estado do Rio de Janeiro - UERJ e professor do Programa de Pós-Graduação em Administração da Universidade Federal Fluminense - UFF.
} 